\title{
oHMint: An Online Mathematics Course and Learning Platform for MINT Students
}

\author{
Helena Barbas ${ }^{1}$, Franz Konieczny², Alexander Lohse ${ }^{1}$, Thomas Schramm* \\ ${ }^{1}$ Universität Hamburg, Fachbereich Mathematik, Bundesstraße 55, 20146 Hamburg, Germany \\ ${ }^{2}$ integral-learning GmbH, Clausewitzstraße 2, 10629 Berlin, Germany \\ ${ }^{3}$ HafenCity Univ. Hamburg, Überseeallee 16, 20457 Hamburg, Germany; *thomas.schramm@hcu-hamburg.de
}

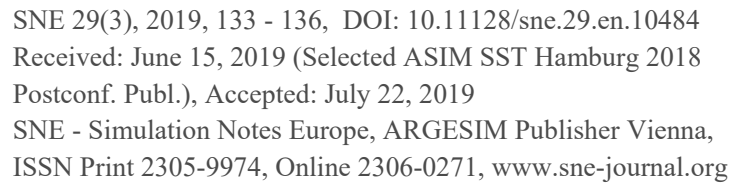

SNE 29(3), 2019, 133 - 136, DOI: 10.11128/sne.29.en.10484 Received: June 15, 2019 (Selected ASIM SST Hamburg 2018 Postconf. Publ.), Accepted: July 22, 2019

SNE - Simulation Notes Europe, ARGESIM Publisher Vienna, ISSN Print 2305-9974, Online 2306-0271, www.sne-journal.org

Abstract. The oHMint project is an initiative with the goal of providing an online course and learning platform for STEM students of higher mathematics. Its flexible design allows it to be used for self-study as well as blended learning scenarios including flipped classrooms. In a pilot project in 2017/18 the chapter Differential Calculus is being produced as a prototype of an oHMint unit. This pilot is organized and funded through the Hamburg Open Online University, with technical support and implementation by integral-learning $\mathrm{GmbH}$. It is intended as a catalyst for the future development of the full oHMint course spanning four semesters. A unique characteristic of oHMint is its broad supporting base among a variety of German institutions in the form of the OMB+consortium.

\section{Introduction}

Engineering mathematics is the main tool to describe the world and to simulate its processes. A profound mathematical education is therefore essential for future engineers and scientists. Digitalization is becoming increasingly important in teaching and studying at university level. More and more online learning tools are being developed to address the current need for educational resources that go well beyond the classical textbook by providing high temporal and spatial flexibility for users while at the same time offering an interactive learning environment.

In this spirit, the oHMint project was initiated through the $\mathrm{OMB}+$ consortium, a group of 14 German institutions of higher education. The acronym stands for online Higher Mathematics (for m)int.
It is the aim of oHMint to provide university students of STEM degree programmes with a modern way of transitioning smoothly from a high school level of mathematics to a bachelor degree level. The OMB+ consortium has already developed the online mathematics bridging course $\mathrm{OMB}+$, which is widely used and recommended as a preparation for those interested in a STEM university degree programme. This experience is a valuable asset for oHMint.

Currently, in a pilot project with a lifespan of 14 months one base unit of oHMint is being created. This serves as an opportunity to test new didactical approaches for mathematics online courses as well as innovative types of exercises addressing the specific needs of the current student generation.

\section{Background of oHMint}

\subsection{OMB+ mathematics bridging course}

The $\mathrm{OMB}+$ consortium has developed and maintains the well-accepted "Online Mathematics Bridging Course Plus" OMB+ [1] under the auspices of the TU9, a group of nine important German technical universities. The course is based on the recommended cosh catalogue [2], which sets a standard of mathematical requirements for freshmen in STEM studies, and should also give an orientation for school teachers in mathematics. The OMB + is text oriented, but includes a large amount of questions, interactive elements, videos and examples with standard solutions, which can be uncovered systematically.

As of today, around 50 German institutions use and recommend the $\mathrm{OMB}+$, which is available in German and English and currently being translated into Chinese. Supplementary chapters covering e.g. stochastics, complex numbers and formal logic have been added and further educational videos are in the making.

The oHMint project uses the same enriched text oriented style and shares similar features. For more information on $\mathrm{OMB}+$ see [1] and [3]. 


\subsection{The Hamburg Open Online University}

The acronym HOOU stands for Hamburg Open Online University (www.hoou.de), a joint initiative of six institutions of higher education in Hamburg: Universität Hamburg (UHH), Hamburg University of Applied Sciences (HAW), Hamburg University of Technology (TUHH), HafenCity University Hamburg (HCU), Hochschule für bildende Künste (HFBK) and the Hochschule für Musik und Theater (HFMT). The Senate of Hamburg founded it in 2015 as the educational branch of "Strategie Digitale Stadt" (Strategy Digital City), an initiative to bundle processes of digitalization within the city.

The HOOU focuses on learners and collaboration for problem solving and develops study material at academic level. Its target groups are not only the custom university students but also interested non-academic persons. Thus, all study material is open as Open Educational Resource and is distributed under a CC license. The production of the first chapter of oHMint is funded by the HOOU and running from November 2017 through December 2018.

\section{Modularisation and Scope}

\subsection{Course structure}

The $\mathrm{OMB}+$ consortium designed the preliminary structure of the curriculum for the full oHMint course. It spans four semesters and aims to cover all the mathematics typically taught in STEM studies at German institutions of higher education. The curriculum was carefully structured, keeping in mind that different (types of) universities have different needs for their respective degree programmes. The course will be available in English and German. With oHMint we aim to create a course that consists of units which can be combined in various ways to cover these needs. The fact that a broad spectrum of institutions is represented in the $\mathrm{OMB}+$ consortium justifies our hope that the final course will be widely accepted within the relevant community. This clearly distinguishes oHMint from existing higher mathematics online courses in Germany.

There are three types of units in oHMint: base units cover standard content and are expected to be included in every higher mathematics course, regardless of the institution it is taught at. Supplementary units go deeper into the (theoretical) background of a base unit, and include more abstract views on base unit concepts as well as more involved parts. Finally, optional units exist for subjects that are not necessarily always part of a higher mathematics course, depending in particular on the study programme and/or institution. The idea is that lecturers will be able to choose and combine the units that are relevant for their classes to provide students with everything they need (but not more).
Parallel to the development of the content of oHMint, a data base is being created that keeps track of all the interconnections between mathematical concepts and results in the units and which will help to ensure the desired modularity of the course.

The units themselves are text-based and consist of lectures, exercises, trainings and final tests. They are supplemented by videos where important concepts or ideas are also shown. Each chapter starts with a motivation for the new mathematical concepts taught such that students develop a sense for the importance of the content they are supposed to learn. Moreover, many interactive elements are being implemented in oHMint, some are discussed in more detail below.

\subsection{Content of the first-semester course}

The learning material from which a lecturer can choose for a first-semester oHMint course consists of:

- Three base units: numbers and functions, differential calculus, integral calculus.

- Four supplementary units: differential calculus, integral calculus, sequences, series.

- Eight optional units: continuity, determination of zeros, L'Hospital's rule, partial fraction decomposition, approximate integration, sequences, series, Fourier analysis.

The scope of the content of each unit has been roughly assessed in terms of the European Credit Transfer and Accumulation System (ECTS) which is commonly used at European institutions of higher education. ECTS points measure the volume of learning based on workload and desired learning outcome. In Germany, one ECTS point is equivalent to 25-30 hours of studying.

The oHMint working group has made an assignment between the content of the chapters of the first-semester course and ECTS points. The base units are assigned 1 ECTS point each, the supplementary units and optional units are assigned 0.5 ECTS. The workload for the corresponding units is estimated to be within the given range.

These values are used as an orientation for the lecturers who use the material for their courses. The actual assignment of credit points to the course is made by the lecturer or their institution.

\section{Didactical Concepts of oHMint}

\subsection{Didactical methods}

The oHMint materials are designed to be used for a wide range of blended learning environments up to fully web based self-learning courses. We selected our didactical methods to specifically suit these environments.

Our guiding principles are a spiral curriculum (after J. Bruner, see [4]), the development of intuitive under- 
standing, awareness, and knowledge of mathematical thinking (see e.g. [5], [6], [7]), and in general an application oriented approach. We follow the ideas of cognitive load theory [8] which focuses on the limited capacity of working memory of students. New ideas and concepts are introduced incrementally, always keeping the cognitive load small and focused. The formally exact representation is the result of the teaching process and not as often a starting point, making the constructive process of mathematical knowledge visible to the students and fostering the awareness between intuitive thinking and correct formulation of mathematics.

Our database of mathematical interconnections (see Section 2.1) supports the development of the spiral curriculum as examples and exercises are shared between the units and viewed from different perspectives.

The revised version of Bloom's taxonomy [6] (see also [15]) is used for a careful evaluation of the learning goals for each unit and exercises and quizzes are designed to reflect this information. This allows the students to assess their learning achievements and the growth of their knowledge continuously. Automatically corrected problems on different levels of content provide them with a differentiated feedback to support the learning process. Different types of exercises support the comprehension of ideas, the stabilization of acquired knowledge or the development of routine skills. Application-oriented exercises from science and engineering impart an understanding of the importance of the methods to the relevant application domains.

\subsection{Serious games and gamification}

Serious games are games that are designed in our context for educational purposes. Gamification can then be defined as the use of typical game design elements and scenarios in non-game contexts, see [9]. We develop a variety of such components for oHMint which create a new incentive for active participation. It is the aim of the current pilot project to test several approaches and choose the most successful ones for implementation in the entire course which will subsequently be developed. Some of our components are:

Badges: We are developing a system of badges that participants receive for completing certain tasks. The positive effect of badges has been documented, see [10]. This will however be an optional element since not everyone likes to be "distracted" by such matters.

Exercises in game form (competitive and non-competitive): For skills that require routine we are developing a gaming approach. The player is given a task such as "what is the derivative of the function $\mathrm{f}(\mathrm{x})$ ". If answered correctly, the player receives points and proceeds. After finishing the game, players can enter their score into a high score list. We are also investigating the option of enabling players to compete against each other in a duel or small groups and the possibility of a "Who wants to be a millionaire?"-styled game. Developing and realizing these ideas and more general the whole course we benefit from close interaction with the e-learning group at Universität Hamburg as well as with student helpers also from the HafenCity University who provide valuable feedback from the target group of oHMint.

\subsection{The advantage of the oHMint concept}

Because of the modularisation (see 2.1) lecturers can design their own course by selecting units depending on their programme-level.

Innovative types of exercises are implemented: audio files train the transition between written and spoken mathematics; in "reversed" exercises the students shall find flaws in a given line of arguments; in "drawing" exercises they are asked to sketch the graph of a function with certain properties. Moreover, there is a large amount of quick checks, i.e. short questions or problems interspersed in the course where students can immediately check if they understood some new content or not.

In the available group instructing mode professors can not only compile a course suitable for their needs but also follow the learning progress of their students in a gradebook overview. Also, a flipped classroom version will be available (see 4). And last, a call centre run by integral-learning $\mathrm{GmbH}$ will be integrated to oHMint as it is already in the $\mathrm{OMB}+$. Thus, participants of oHMint can contact a call centre for mathematical questions from 10 am till $8 \mathrm{pm}$ via internal chat, telephone, skype (telephone and chat) or internal forum as a free service. For more details on our didactical methods see [11].

\section{Flipped Classroom}

At many universities a typical mathematics lecture for engineers suffers from low intrinsic motivation of the students, their low competence in school mathematics, (which we hope to enhance through $\mathrm{OMB}+$ ) and the procrastinating study style of many students.

Flipped classroom is an interactive teaching model that addresses this problem. The information and content instruction takes place outside of class time and class time is used for practice oriented activities. The concept has been successfully introduced in university mathematics and evaluated in recent years [12, 13, 14]. It has been shown that the average performance of students in exams is at least equal to the one of students instructed with traditional methods. Moreover, through flipped classroom students tend to have a better under- 
standing of underlying concepts. The gap between better and weaker students tends to get smaller while the well performing students perform equally well as or better than with traditional classroom lectures.

The students get preparatory material focusing on the basic concepts with a set of key questions guiding their studies and a quiz of control questions that have to be answered before class time. The quizzes are automatically corrected and give students helpful feedback and encourage them to prepare.

In-class time is used for interactivity with more challenging problems that are followed up with homework.

In winter term 2018/19 the first prototype module for differential calculus will be used in a flipped classroom context for a freshmen class of Mathematics in a Geodesy and Geoinformation course at the HCU. The class time will be split. The first half will be an interactive session to handle feedback questions from students and presentations from students. The second half will be used for group work on special exercises to solidify and deepen the gained new mathematical competencies.

Implementing the first base unit of oHMint into a real teaching scenario at this early stage will result in valuable experience and feedback for the further development of the oHMint course.

\section{Conclusions}

As explained above, the production of the first oHMint base unit Differential Calculus is funded by the HOOU. It is meant as a sample for the remaining units of the course, testing new approaches in digital teaching and innovative types of exercises. The oHMint working group, currently a subgroup of the $\mathrm{OMB}+$ consortium, intends to create attention for the project and raise further funding through this sample unit. Other working groups are encouraged to join the oHMint project and/or produce an oHMint unit themselves.

The main assets of oHMint are its flexibility in terms of teaching style, ranging from self-study to flipped classroom settings. Each unit will be translated into English once it is completed. A preliminary version of Differential Calculus will be put to the test in the winter term 2018/19 at HCU Hamburg as a flipped classroom version, feedback from HCU students and lecturers will be incorporated into the future development of oHMint.

Overall, we believe that oHMint poses an important step in the digitalization of STEM education in Germany. The broad supporting base guiding its development ensures that it is tailor-made for the needs of lecturers and students alike, and its modular structure makes it suitable for all institutions.
Acknowledgements. We gratefully acknowledge the financial support of the HOOU for the current project, the guidance and input of the $\mathrm{OMB}+$ consortium (especially Volker Bach) in the development of oHMint and support beyond the technical lead by integral-learning $\mathrm{GmbH}$.

\section{References}

[1] $\mathrm{OMB}+$ www.ombplus.de

[2] Braun I, Schröder J, et al. cosh cooperation Schule: Hochschule - Mindestanforderungskatalog Mathematik (Version 2.0), 2014. https://lehrerfortbildung- bw.de/u_ matnatech/mathematik/bs/bk/cosh/katalog/in- dex.html

[3] Barbas H, Schramm T. The Hamburg Online Math Test MINTFIT for Prospective Students of STEM Degree Programmes, MSOR Connections, 2018, 16(3): 43-51.

[4] Bruner J. The Process of Education, Harvard University Press. Cambridge, Mass., USA, 1960.

[5] Pintrich P R. The Role of Metacognitive Knowledge in Learning, Teaching and Assessing, Theory into Practice, 2002, 41(4): Revising Bloom's Taxonomy, 219-225.

[6] Krathwohl D R. A Revision of Bloom's Taxonomy: An Overview, 2002. https://www.depauw.edu/files/resources/krathwohl.pdf

[7] Zech F. Grundkurs Mathematikdidaktik, Beltz Verlag, Weinheim und Basel, 1996.

[8] de Jong T. Cognitive load theory, educational research, and instructional design: some food for thought, Instructional Science, 2010, 38: 105-134.

[9] Deterding S, Dixon D, Khaled R, Nacke L E. Gamification: Toward a definition, CHI 2011, 2011, Vancouver, Canada.

[10] Denny P. The Effect of Virtual Achievements on Student Engagement, CHI 2013: Changing Perspectives, 2013, Paris, France, pp. 763-772.

[11] Barbas H, Gasser I, Konieczny F, Lohse A, Seiler R. oHMint: Online Higher Mathematics for MINT Students - An Online Mathematics Course and Learning Platform, Preprint, to appear in the Proceedings of the $46^{\text {th }}$ SEFI Annual Conference, 2018, Copenhagen, Denmark.

[12] Epstein. The Calculus Concept Inventory -- Measurement of the Effect of Teaching Methodology in Mathematics, Notices of the AMS 2013, 60(8), https://www.ams.org/ journals/notices/201308/rnoti- p1018.pdf

[13] Maciejewski W. Flipping the calculus classroom: an evaluative study, Teaching Mathematics and its Applications: An International Journal of the IMA, Volume 35, Issue 4, 1 December 2016, Pages 187-201, https://doi.org/10.1093/teamat/hrv019

[14] Cronhjort M, Filipsson L. Weurlander M. Improved engagement and learning in flipped-classroom calculus, Teaching Mathematics and its Applications: An International Journal of the IMA, , hrx007, https://doi.org/10.1093/teamat/hrx007

[15] Anderson L W, Krathwohl D. (eds.) A Taxonomy for Learning, Teaching, and Assessing: a Revision of Bloom's Taxonomy of Educational Objectives. New York Longman, 2001. 